\title{
The Effect of Captopril on Impaired Wound Healing in Experimental Diabetes
}

\author{
Ehsan Zandifar, ${ }^{1,2}$ Sajedeh Sohrabi Beheshti, 1, 2,3 \\ Alireza Zandifar, ${ }^{1,2}$ and Shaghayegh Haghjooy Javanmard ${ }^{1}$ \\ ${ }^{1}$ Physiology Research Center, Department of Physiology, Isfahan University of Medical Sciences, Isfahan, Iran \\ ${ }^{2}$ Isfahan Medical Student Research Center, Isfahan University of Medical Sciences, Isfahan, Iran \\ ${ }^{3}$ Department of Physiology, Isfahan Payame Noor University, Isfahan, Iran
}

Correspondence should be addressed to Shaghayegh Haghjooy Javanmard, shaghayeghhaghjoo@yahoo.com

Received 30 January 2012; Revised 25 April 2012; Accepted 25 May 2012

Academic Editor: Leon Bach

Copyright () 2012 Ehsan Zandifar et al. This is an open access article distributed under the Creative Commons Attribution License, which permits unrestricted use, distribution, and reproduction in any medium, provided the original work is properly cited.

\begin{abstract}
We aimed to investigate whether oral administration of captopril modulate wound healing, nitric oxide (NO), and vascular endothelial growth factor (VEGF) concentration in wound fluid of diabetic rats. 48 male Sprague-Dawley rats were divided in four groups $(n=12)$. The 36 rats were rendered diabetic by streptozotocin. The animals of the first and second groups received 25 and $50 \mathrm{mg} / \mathrm{kg} /$ day captopril, respectively, (DM-cap25 and DM-cap50). The animals of the third group were treated by distilled water (DM-control). Control rats had no intervention. The wound fluid level of NO and VEGF were measured. Wound specimens were investigated histopathologically. At the 5th day, there was significantly more $\mathrm{NO}_{x}$ in wound fluid of DM-cap25 compared to other groups. At the 7th day, both captopril-treated groups had more $\mathrm{NO}_{x}$ in wound fluid compared to other groups. At the 11th day, both captopril-treated groups had more $\mathrm{NO}_{x}$ in wound fluid compared to DM-control group. VEGF concentration was significantly higher in both captopril-treated groups versus DM-control group $(P<.05)$. There were significant higher wound healing scores in captopril-treated groups compared with DM-control group $(P<.05)$. These results suggest that captopril might be useful in diabetic wound healing.
\end{abstract}

\section{Introduction}

Impaired wound healing is a substantial problem in both type 1 and type 2 diabetes. The wound is often resistant to conventional wound management and may ultimately threaten limb viability [1]. Analysis of the diabetic wound microenvironment has revealed that healing impairment is characterized by a number of local cytokine and cellular abnormalities such as reduced angiogenesis, decreased collagen synthesis and wound breaking strengths [2]. Growth factors such as platelet-derived growth factor (PDGF) and vascular endothelial growth factor (VEGF) have been found to be diminished in the diabetic wound, whereas levels of matrix metalloproteinase and superoxide are elevated in diabetic wound fluid $[3,4]$.

The diabetic wound also demonstrates a number of abnormalities reminiscent of endothelial dysfunction. For example, reduced wound nitric oxide (NO) concentration has been shown in experimental diabetic animal models of acute cutaneous wound healing [5]. Diabetic wounds have also evident reduction in cutaneous blood flow, and abnormal angiogenesis supports the theory of impaired endothelial function and consequently delayed wound repair $[6,7]$. So, restoration of endothelial function may be a good therapeutic approach in the diabetic wound healing process.

Angiotensin-converting enzyme inhibitors (ACEIs) have known restorative effects on endothelial cell functions. ACEIs enhanced endothelial cell survival through activation of prosurvival signals such as Akt phosphorylation and endothelial NO synthase (eNOS) expression. However, ACEIs block the production of angiotensin II (Ang II) which has many proangiogenic activities $[8,9]$. ACEIs are recommended for the prevention of chronic kidney disease in diabetic patients, while the effect of ACEIs on diabetic wound healing is still unclear. 
A few studies have investigated the potential safety concerns with respect to angiogenesis. We aimed to investigate whether oral administration of captopril modulate wound healing and NO and VEGF concentration in wound fluid in an acute incisional wound model in diabetic rats.

\section{Methods}

2.1. Animals and Experimental Protocol. 48 male SpragueDawley rats, weighing 180 to $220 \mathrm{~g}$, from Razi Institute of Iran, were housed one per cage, maintained under controlled environmental conditions (12-hour light/dark cycle, temperature approximately $23^{\circ} \mathrm{C}$ ), and provided with standard laboratory food and water ad libitum. The study protocol was approved by Institutional Animal Ethics Committee according to principles of laboratory animal care [10].

Diabetes was induced by a single $65 \mathrm{mg} / \mathrm{kg}$ intravenous injection of streptozotocin (STZ, Sigma, USA) in salinesodium citrate buffer (Sigma, Inc., St. Louis, MO, USA, pH $4.5)$ to 36 rats. Blood glucose levels were measured using a glucometer (GR-102, TERUMO Co., Tokyo, Japan). Two weeks after STZ injection, animals with blood glucose levels above $300 \mathrm{mg} / \mathrm{dL}$ were defined as diabetic and used in the study. The animals were divided into four groups: three diabetic and one nondiabetic. Each group had 12 animals. The animals of the first diabetic group received captopril (25 mg/kg/day) (DM-cap25). The animals of the second diabetic group received captopril ( $50 \mathrm{mg} / \mathrm{kg} /$ day) (DM-cap50), while the animals of the third diabetic group received only distilled water (DM-control) for 11 days through gavage. The fourth group, consisting of nondiabetic rats, were given distilled water, by gavage for 11 days (non-DM-control). The doses were selected based on work by other studies $[11,12]$.

In the first day of the study, after general anesthesia with sodium pentobarbital ( $80 \mathrm{mg} / \mathrm{kg}$, ip), hair on the back was shaved and the skin was washed with a povidone-iodine solution and then wiped with sterile water. Full-thickness wounds $\left(1 \mathrm{~cm}^{2}\right)$ were made on the dorsum of the rats.

By the end of the study, the fasting plasma glucose (FPG) was measured again in all animals by enzymatic method (Boehringer Mannheim, Germany).

2.2. Determination of VEGF and NO in Wounds. Two samples of wound fluid were collected using sterile nitrate-free absorbent paper strips placed on the edges of the wound for $10 \mathrm{~min}$, in order to measure VEGF in the 5 th day and NO levels in 5 th, 7 th, and 11th days of the study. This method for the measurement has been validated for other sample types, particularly for tears $[13,14]$. For VEGF measurement, protein elution from the Shirmer strips was performed by stirring the strips in $0.5 \mathrm{~mL}$ of buffer $(50 \mathrm{mM}$ Tris, $50 \mathrm{mM}$ $\mathrm{NaCl}, 0.05 \%$ Brij 35, pH 7.6) for at least $2 \mathrm{~h}$ at $+4^{\circ} \mathrm{C}$. For wound fluid $\mathrm{NO}_{x}$ determinations, filter paper was placed in $0.5 \mathrm{~mL}$ of distilled water [15].

The amount of VEGF in wound fluid was measured using enzyme-linked immunosorbent assay using available reagents and recombinant standards (R\&D Systems, Minneapolis, MN, USA) according to manufactures instruction
TABLE 1: Criteria to evaluate histological scores of wound healing.

\begin{tabular}{|c|c|}
\hline Scores & \\
\hline $1-3$ & $\begin{array}{l}\text { None to minimal cell accumulation, no granulation } \\
\text { tissue or epithelial travel }\end{array}$ \\
\hline $4-6$ & $\begin{array}{l}\text { Thin immature granulation, that is, dominated by } \\
\text { inflammatory cells but has few fibroblasts, capillaries, } \\
\text { or collagen deposition, minimal epithelial migration }\end{array}$ \\
\hline $7-9$ & $\begin{array}{l}\text { Moderately thick granulation tissue can range from } \\
\text { being dominated by inflammatory cells to more } \\
\text { fibroblasts and collagen deposition, extensive } \\
\text { neovascularization, epithelium can range from } \\
\text { minimal to moderate migration }\end{array}$ \\
\hline $10-12$ & $\begin{array}{l}\text { Thick, vascular granulation tissue dominated by } \\
\text { fibroblasts and extensive collagen deposition, } \\
\text { epithelium partially to completely covering the wound }\end{array}$ \\
\hline
\end{tabular}

only in 5th day samples. The VEGF assay has a minimum sensitivity of $3.0 \mathrm{pg} / \mathrm{mL}$. The total nitrite level of wound fluid was measured using the Griess assay after conversion of $\mathrm{NO}_{3}$ to $\mathrm{NO}_{2}$ with the $\mathrm{NO}_{3}$ reductase enzyme as described previously [16].

2.3. Histologic Examination. All wound tissue specimens were fixed in $10 \%$ neutral-buffered formalin for at least $24 \mathrm{~h}$ at room temperature. After fixation, vertical sections to the anterior-posterior axis of the wound were dehydrated in graded ethanol, cleared in xylene, and embedded in paraffin. Four-micron-thick sections were mounted on glass slides, dewaxed, rehydrated to distilled water, and stained with hematoxylin and eosin. For histological evaluation, all slides were examined by two pathologists, without knowledge of the prior treatment, under a microscope from $\times 20$ to $\times 100$ magnification. The histological score adopted in this study was performed according to the previous study concerning wound healing in experimental models. The criteria used as histological scores of wound healing are summarized in Table 1 [17].

2.4. Statistical Analysis. All data are expressed as the mean \pm the standard deviation (mean $\pm \mathrm{SD}$ ). A statistical software package, SPSS (version 14), was used to perform statistical analysis. The data were tested for normality and homogeneity of variance. Data were analyzed by analysis of variance (ANOVA), followed by a post hoc multiple comparison. For the histological results, statistical analysis was performed using kruskal-Wallis test. Statistical significance was accepted at $P<0.05$.

\section{Results}

The mean of FPG levels has been illustrated in Table 2 . By the end of the study, there was no significant difference between diabetic groups, while all of the diabetic groups had significantly more FPG than non-DM control group $(P<$ $0.001)$. 
TABLE 2: Mean levels of fasting plasma glucose in four study groups.

\begin{tabular}{lllll}
\hline Group & DM-cap25 & DM-cap50 & DM-control & $\begin{array}{c}\text { Non-DM- } \\
\text { control }\end{array}$ \\
\hline $\begin{array}{l}\text { Fasting plasma } \\
\text { glucose (mg/dL) }\end{array}$ & $651 \pm 89$ & $526 \pm 107$ & $559 \pm 59$ & $119 \pm 13^{*}$ \\
\hline
\end{tabular}

$* P<0.05$.

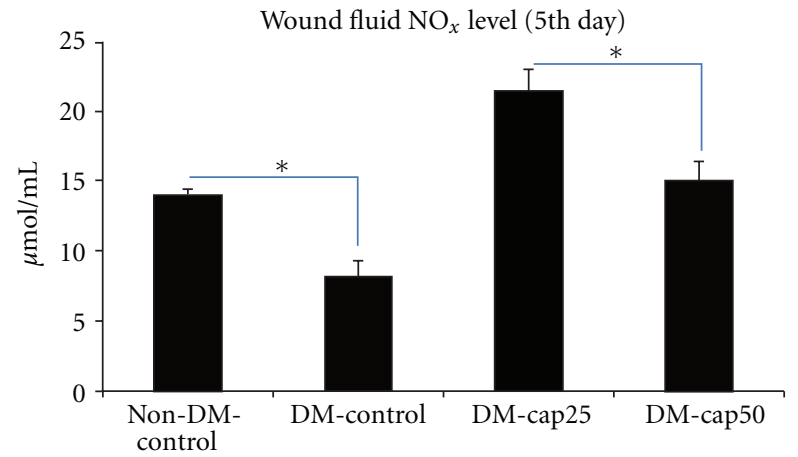

FIGURE 1: The total nitrite level of wound fluid was measured using Griess assay at the 5th day of study. Non-DM-control: nondiabetic rats which have received distilled water. DM-control diabetic rats which have received distilled water. DM-cap25: diabetic rats which have received captopril $(25 \mathrm{mg} / \mathrm{kg} /$ day $)$. DM-cap50: diabetic rats which have received captopril $(50 \mathrm{mg} / \mathrm{kg} /$ day $)$. Data are reported in $\mu \mathrm{mol} / \mathrm{L} \pm \mathrm{SD}\left({ }^{*} P<0.05\right)$.

Total nitrite/nitrate concentrations $\left(\mathrm{NO}_{x}\right)$ in biological fluids can be used as an index of NOS activity [18]. As it has been illustrated in Figure 1, at the 5th day DM-cap25 group had significantly more wound fluid $\mathrm{NO}_{x}$ level than other groups $(P<0.001)$. DM-cap50 group had significantly more wound fluid $\mathrm{NO}_{x}$ level than DM-control group $(P<0.001)$, though there was no significant difference between DMcap50 group compared to non-DM-control group. The $\mathrm{NO}_{x}$ level of wound fluid in non-DM-control group was significantly more than DM-control group $(P<0.001)$.

At the 7th day, the DM-cap25 group had significantly more wound fluid $\mathrm{NO}_{x}$ level than DM-control $(P<0.001)$ and non-DM-control groups $(P<0.003)$, while the difference of wound fluid $\mathrm{NO}_{x}$ level between DM-cap25 group and DM-cap50 group was not significant. The $\mathrm{NO}_{x}$ level of wond fluid in DM-cap50 group was significantly more than DM-control group $(P<0.001)$ and non-DM-control group $(P<0.05)$. Non-DM-control group had significantly more wound fluid $\mathrm{NO}_{x}$ level than DM-control group $(P<0.05)$ (Figure 2).

At the 11th day, the wound fluid $\mathrm{NO}_{x}$ level of DMcap 25 group was more than other groups but the difference only between DM-cap25 group and DM-control group was significant $(P<0.002)$. The $\mathrm{NO}_{x}$ level of wound fluid in DMcap50 group was significantly more than DM-control group $(P<0.007)$. Non-DM-control group had significantly more wound fluid $\mathrm{NO}_{x}$ level than DM-control group $(P<0.03)$ (Figure 3).

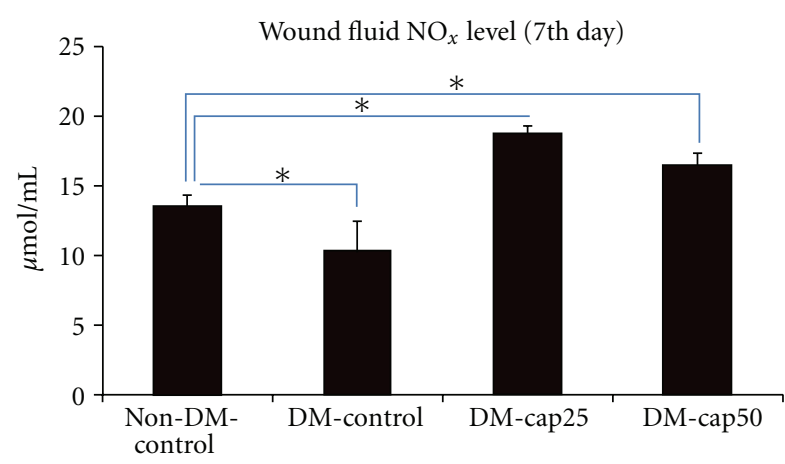

FIGURE 2: The total nitrite level of wound fluids was measured using Griess assay at the 7th day of study. Non-DM-control: nondiabetic rats which have received distilled water. DM-control: diabetic rats which have received distilled water. DM-cap25: diabetic rats which have received captopril $(25 \mathrm{mg} / \mathrm{kg} / \mathrm{day})$. DM-cap50: diabetic rats which have received captopril $(50 \mathrm{mg} / \mathrm{kg} /$ day $)$. Data are reported in $\mu \mathrm{mol} / \mathrm{L} \pm \mathrm{SD}\left({ }^{*} P<0.05\right)$.

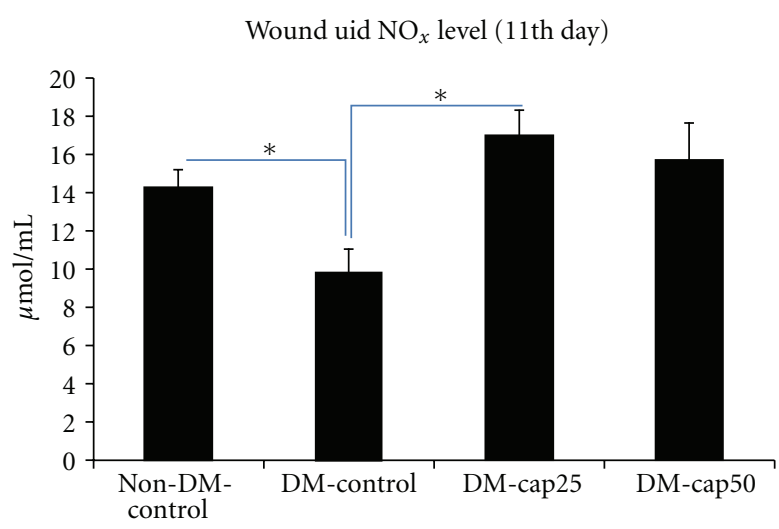

Figure 3: The total nitrite level of wound fluids was measured using Griess assay at the 11th day of study. Non-DM-control: nondiabetic rats which have received distilled water. DM-control: diabetic rats which have received distilled water. DM-cap25: diabetic rats which have received captopril $(25 \mathrm{mg} / \mathrm{kg} / \mathrm{day})$. DM-cap50: diabetic rats which have received captopril $(50 \mathrm{mg} / \mathrm{kg} / \mathrm{day})$. Data are reported in $\mu \mathrm{mol} / \mathrm{L} \pm \mathrm{SD}\left({ }^{*} \mathrm{P}<0.05\right)$.

The VEGF levels of wound fluid were only measured in the 5th day of the study. DM-cap25 group VEGF concentration was significantly higher than other groups $(P<0.02)$. VEGF concentration DM-cap50 group was significantly more than DM-control group $(P<0.05)$. Non-DM-control group had more VEGF concentration than DM-cap50 and DM-control groups, but the difference was significantly between non-DM-control and DM-control groups $(P<0.002)$ (Figure 4).

There was no significant difference in wound healing score between captopril-treated groups and non-DM-control group. The wound healing score in captopril-treated groups and non-DM-control group was significantly more than DM-control group $(P<0.05)$ (Figure 5). 


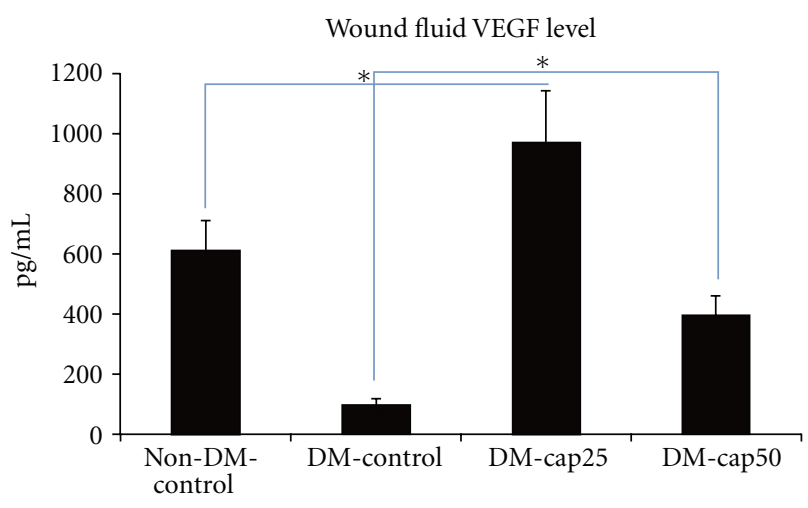

Figure 4: The VEGF level of wounds fluids was measured using ELISA at the 5th day of the study. Non-DM-control: nondiabetic rats which have received distilled water. DM-control: diabetic rats which have received distilled water. DM-cap25: diabetic rats which have received captopril $(25 \mathrm{mg} / \mathrm{kg} /$ day $)$. DM-cap50: diabetic rats which have received captopril $(50 \mathrm{mg} / \mathrm{kg} / \mathrm{day})$. Data are reported in $\mathrm{pg} / \mathrm{mL} \pm \mathrm{SD}\left({ }^{*} P<0.05\right)$.

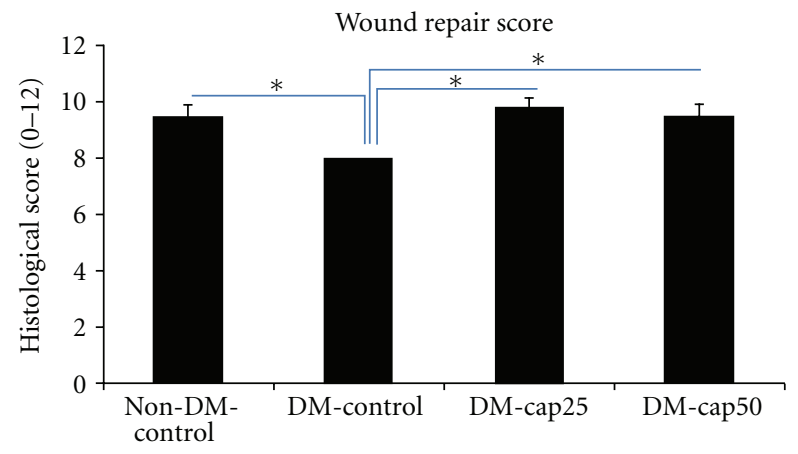

FIGURE 5: The histological scores of wound healing were examined by two pathologists, without knowledge of the prior treatment. Non-DM-control: nondiabetic rats which have received distilled water. DM-control: diabetic rats which have received distilled water. DM-cap25: diabetic rats which have received captopril $(25 \mathrm{mg} /$ $\mathrm{kg}$ /day). DM-cap50: diabetic rats which have received captopril $(50 \mathrm{mg} / \mathrm{kg} /$ day $)$. Data are reported in mean scores $\pm \mathrm{SD}(* P<0.05)$.

\section{Discussion}

The wound healing process involves a complex interplay of cells, mediators, growth factors, and cytokines [19]. The diabetic wound demonstrates a number of aberrations suggestive of localized endothelial dysfunction. Therefore, targeting of endothelial dysfunction may represent a promising focus for treatment of the diabetic wound. So, in this study, we tested whether captopril as a known effective drug on the endothelial dysfunction as well as frequently used drug in diabetic patients influences diabetic wound healing.

In our study, there was a significant decreased level of NO in wound fluid of diabetic rats. Decreased level of NO parallel to impaired healing has been shown in experimental diabetic animal models of wound healing [5]. Furthermore, abnormalities in endothelial and inducible NOS expression have been demonstrated in diabetic animal wound tissue when compared to nondiabetic counterparts [20,21]. Captopril supplementation resulted in significantly increased levels of NO in wound fluid. ACEIs can increase NO production through increased available active kinins [22]. It has been shown that treatment of diabetic patients with ACEIs can improve NOS-dependent responses of large peripheral vessels $[23,24]$.

The significant different levels of wound fluid NO between the two doses of the ACE inhibitor in 5th day of the study may show a different dose-dependent effect of ACEIs on the NO.

It may be explained by an inverse relationship between the expression/activity of ACE and eNOS via feedback regulation [25]. It has been shown that the regulation of ACE is correlated with changes of the expression and activity of eNOS. ACE expression/activity is increased when eNOS expression/activity is decreased. Conversely, a decreased ACE expression/activity is observed when eNOS expression/activity is increased. Thus, it can be postulated that more ACE inhibition may be associated with more NO production. Furthermore, more ACE inhibition leads to further increase of endothelial-derived kinins and consequently more NO production. In agreement with our results, several other studies have reported dose-dependent effect of ACEIs on NO production [26].

VEGF concentration was significantly higher in both captopril-treated groups compared to both DM and non-DM control groups. It has been shown that impaired angiogenesis in diabetes is related to VEGF signaling and in inflammationrelated pathway [27].

The results of several studies suggest that the effect of ACEIs on angiogenesis is related to ACEI-induced potentiation of endogenous bradykinin [28]. Li et al. showed that bradykinin receptor1 (BK-B1R) antagonist severely suppressed the imidapril-induced angiogenesis in angiotensin receptor la knockout (AT1aKO) mice, while NOS inhibitor moderately attenuated the imidapril-mediated angiogenesis [29]. Furthermore, it has been shown that proangiogenic effects of ACEIs are blunted in BK-B2R receptor-deficient diabetic mice [30].

Similar to our results, Gao and Yu have shown that ACEI treatment resulted in increased level of VEGF mRNA and protein expression by 1.44 - and 1.30 -fold compared with untreated diabetic rats in hind limb ischemic model [31]. Though, the combination of a BK-B1R antagonist to ACEItreated group made the expression of VEGF decreased in their study.

In addition, $\mathrm{NO}$ can induce VEGF synthesis through an HIF-1-mediated pathway, and VEGF enhances NO production by eNOS $[32,33]$. These actions may lead to promotion of angiogenesis.

Furthermore, it has been shown that proangiogenic actions of Ang II could be mediated via the angiotensin type 1 (AT1) receptor, in part, through activation of VEGFrelated pathway [34].

Several studies suggest that Ang II promotes cell proliferation and blood vessel growth [35, 36]. In line of these evidences, it can be speculated that low dose of ACEIs would be more effective in wound healing. It has been shown that 
very low dose of perindopril induces an early and sustained effect on the revascularization in ischemic tissue through a VEGF-dependent pathway [36].

In conclusion, it seems that low dose of captopril is safe and effective in diabetic wound healing. However, our study has some limitations. It would be better to study further doses of captopril and have a captopril-treated nondiabetic control group. Further studies especially welldesigned clinical trials are required to confirm this finding.

\section{Acknowledgments}

This study was supported by Isfahan University of Medical Sciences, Isfahan, Iran (Grant no. 384151). The authors would like to thank Dr. Mohammad Motaghi (Medical Student Research Center, Isfahan University of Medical Sciences) and Dr. Morteza Rezaei (Medical Student Research Center, Isfahan University of Medical Sciences) who contributed to this study. All authors have read and approved the content of the paper. The authors have no competing interests.

\section{References}

[1] D. G. Greenhalgh, "Wound healing and diabetes mellitus," Clinics in Plastic Surgery, vol. 30, no. 1, pp. 37-45, 2003.

[2] F. Cosentino and T. F. Lüscher, "Endothelial dysfunction in diabetes mellitus," Journal of Cardiovascular Pharmacology, vol. 32, no. 3, pp. S54-S61, 1998.

[3] R. Blakytny and E. Jude, "The molecular biology of chronic wounds and delayed healing in diabetes," Diabetic Medicine, vol. 23, no. 6, pp. 594-608, 2006.

[4] R. Lobmann, A. Ambrosch, G. Schultz, K. Waldmann, S. Schiweck, and H. Lehnert, "Expression of matrix-metalloproteinases and their inhibitors in the wounds of diabetic and non-diabetic patients," Diabetologia, vol. 45, no. 7, pp. 10111016, 2002.

[5] M. R. Schäffer, U. Tantry, P. A. Efron, G. M. Ahrendt, F. J. Thornton, and A. Barbul, "Diabetes-impaired healing and reduced wound nitric oxide synthesis: a possible pathophysiologic correlation," Surgery, vol. 121, no. 5, pp. 513-519, 1997.

[6] M. Kalani, J. Ostergren, K. Brismar, G. Jörneskog, and B. Fagrell, "Transcutaneous oxygen tension and toe blood pressure as predictors for outcome of diabetic foot ulcers," Diabetes Care, vol. 22, no. 1, pp. 147-151, 1999.

[7] A. Martin, M. R. Komada, and D. C. Sane, "Abnormal angiogenesis in diabetes mellitus," Medicinal Research Reviews, vol. 23, no. 2, pp. 117-145, 2003.

[8] C. C. Chua, R. C. Hamdy, and B. H. L. Chua, "Upregulation of vascular endothelial growth factor by angiotensin II in rat heart endothelial cells," Biochimica et Biophysica Acta, vol. 1401, no. 2, pp. 187-194, 1998.

[9] R. Tamarat, J. S. Silvestre, M. Duriez, and B. I. Levy, "Angiotensin II angiogenic effect in vivo involves vascular endothelial growth factor- and inflammation-related pathways," Laboratory Investigation, vol. 82, no. 6, pp. 747-756, 2002.

[10] Office of Laboratory Animal Welfare, Office of Extramural Research, National Institutes of Health, Public Health Service Policy on Human Care and Use of Laboratory Animals, 2002, http://grants1.nih.gov/grants/olaw/references/phspol.htm.
[11] D. Yavuz, B. Küçükkaya, G. Haklar, O. Ersöz, E. Akoğlu, and S. Akalin, "Effects of captopril and losartan on lipid peroxidation, protein oxidation and nitric oxide release in diabetic rat kidney," Prostaglandins Leukotrienes and Essential Fatty Acids, vol. 69, no. 4, pp. 223-227, 2003.

[12] J. Duarte, A. Martinez, A. Bermejo et al., "Cardiovascular effects of captopril and enalapril in obese Zucker rats," European Journal of Pharmacology, vol. 365, no. 2-3, pp. 225-232, 1999.

[13] C. D. Barro, J. P. Romanet, A. Fdili, M. Guillot, and F. Morel, "Gelatinase concentration in tears of corneal-grafted patients," Current Eye Research, vol. 17, no. 2, pp. 174-182, 1998.

[14] M. Muller, C. Trocme, B. Lardy, F. Morel, S. Halimi, and P. Y. Benhamou, "Matrix metalloproteinases and diabetic foot ulcers: the ratio of MMP-1 to TIMP-1 is a predictor of wound healing," Diabetic Medicine, vol. 25, no. 4, pp. 419-426, 2008.

[15] J. V. Boykin and C. Baylis, "Hyperbaric oxygen therapy mediates increased nitric oxide production associated with wound healing: a preliminary study," Advances in Skin \& Wound Care, vol. 20, no. 7, pp. 382-388, 2007.

[16] S. Haghjooyjavanmard, M. Nematbakhsh, A. Monajemi, and M. Soleimani, "von Willebrand factor, C-reactive protein, nitric oxide, and vascular endothelial growth factor in a dietary reversal model of hypercholesterolemia in rabbit," Biomedical Papers of the Medical Faculty of the University Palacký, Olomouc, Czechoslovakia, vol. 152, no. 1, pp. 91-95, 2008.

[17] K. Maruyama, J. Asai, M. Ii, T. Thorne, D. W. Losordo, and P. A. D'Amore, "Decreased macrophage number and activation lead to reduced lymphatic vessel formation and contribute to impaired diabetic wound healing," American Journal of Patho$\log y$, vol. 170, no. 4, pp. 1178-1191, 2007.

[18] S. H. Javanmard, M. Nematbakhsh, and A. Monajemi, "LArginine supplementation influenced nitrite but not nitrate and total nitrite in rabbit model of hypercholesterolemia," Iranian Biomedical Journal, vol. 12, no. 3, pp. 179-184,2008.

[19] R. A. F. Clark, "Cutaneous tissue repair: basic biologic considerations. I," Journal of the American Academy of Dermatology, vol. 13, no. 5, pp. 701-725, 1985.

[20] M. B. Witte, F. J. Thornton, U. Tantry, and A. Barbul, "Larginine supplementation enhances diabetic wound healing: involvement of the nitric oxide synthase and arginase pathways," Metabolism, vol. 51, no. 10, pp. 1269-1273, 2002.

[21] H. Kämpfer, J. Pfeilschifter, and S. Frank, "Expression and activity of arginase isoenzymes during normal anddiabetesimpaired skin repair," Journal of Investigative Dermatology, vol. 121, no. 6, pp. 1544-1551, 2003.

[22] M. R. Kichuk, X. Zhang, M. Oz et al., "Angiotensin-converting enzyme inhibitors promote nitric oxide production in coronary microvessels from failing explanted human hearts," American Journal of Cardiology, vol. 80, no. 3, pp. 137A-142A, 1997.

[23] G. O’Driscoll, D. Green, J. Rankin, K. Stanton, and R. Taylor, "Improvement in endothelial function by angiotensin converting enzyme inhibition in insulin-dependent diabetes mellitus," The Journal of Clinical Investigation, vol. 100, no. 3, pp. 678-684, 1997.

[24] C. Cheetham, J. Collis, G. O'Driscoll, K. Stanton, R. Taylor, and D. Green, "Losartan, an angiotensin type 1 receptor antagonist, improves endothelial function in non-insulindependent diabetes," Journal of the American College of Cardio$\log y$, vol. 36, no. 5, pp. 1461-1466, 2000. 
[25] M. Takemoto, K. Egashira, M. Usui et al., "Important role of tissue angiotensin-converting enzyme activity in the pathogenesis of coronary vascular and myocardial structural changes induced by long-term blockade of nitric oxide synthesis in rats," The Journal of Clinical Investigation, vol. 99, no. 2, pp. 278-287, 1997.

[26] L. Ghiadoni, D. Versari, A. Magagna et al., "Ramipril dosedependently increases nitric oxide availability in the radial artery of essential hypertension patients," Journal of Hypertension, vol. 25, no. 2, pp. 361-366, 2007.

[27] V. Tchaikovski, S. Olieslagers, F. D. Böhmer, and J. Waltenberger, "Diabetes mellitus activates signal transduction pathways resulting in vascular endothelial growth factor resistance of human monocytes," Circulation, vol. 120, no. 2, pp. 150-159, 2009.

[28] J. S. Silvestre, S. Bergaya, R. Tamarat, M. Duriez, C. M. Boulanger, and B. I. Levy, "Proangiogenic effect of angiotensin-converting enzyme inhibition is mediated by the bradykinin B2 receptor pathway," Circulation Research, vol. 89, no. 8, pp. 678-683, 2001.

[29] P. Li, T. Kondo, Y. Numaguchi et al., "Role of bradykinin, nitric oxide, and angiotensin II type 2 receptor in imidapril-induced angiogenesis," Hypertension, vol. 51, no. 2, pp. 252-258, 2008.

[30] P. Gohlke, I. Kuwer, A. Schnell, K. Amann, G. Mall, and T. Unger, "Blockade of bradykinin $\mathrm{B} 2$ receptors prevents the increase in capillary density induced by chronic angiotensinconverting enzyme inhibitor treatment in stroke-prone spontaneously hypertensive rats," Hypertension, vol. 29, no. 1, pp. 478-482, 1997.

[31] L. Gao and D. M. Yu, "Molecular mechanism of limbs' postischemic revascularization improved by perindopril in diabetic rats," Chinese Medical Journal, vol. 121, no. 21, pp. 21292133, 2008.

[32] J. Dulak and A. Józkowicz, "Regulation of vascular endothelial growth factor synthesis by nitric oxide: facts and controversies," Antioxidants and Redox Signaling, vol. 5, no. 1, pp. 123132, 2003.

[33] M. I. Lin and W. C. Sessa, "Vascular endothelial growth factor signaling to endothelial nitric oxide synthase: more than a FLeeTing moment," Circulation Research, vol. 99, no. 7, pp. 666-668, 2006.

[34] D. A. Walsh, D. E. Hu, J. Wharton, J. D. Catravas, D. R. Blake, and T. P. D. Fan, "Sequential development of angiotensin receptors and angiotensin I converting enzyme during angiogenesis in the rat subcutaneous sponge granuloma," British Journal of Pharmacology, vol. 120, no. 7, pp. 1302-1311, 1997.

[35] R. Tamarat, J. S. Silvestre, N. Kubis et al., "Endothelial nitric oxide synthase lies downstream from angiotensin II-induced angiogenesis in ischemic hindlimb," Hypertension, vol. 39, no. 3, pp. 830-835, 2002.

[36] J. S. Silvestre, N. Kamsu-Kom, M. Clergue, M. Duriez, and B. I. Lévy, "Very-low-dose combination of the angiotensinconverting enzyme inhibitor perindopril and the diuretic indapamide induces an early and sustained increase in neovascularization in rat ischemic legs," Journal of Pharmacology and Experimental Therapeutics, vol. 303, no. 3, pp. 1038-1043, 2002. 


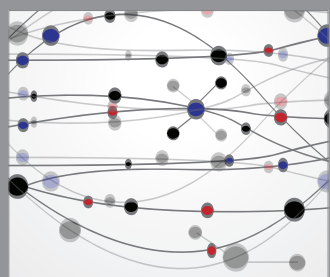

The Scientific World Journal
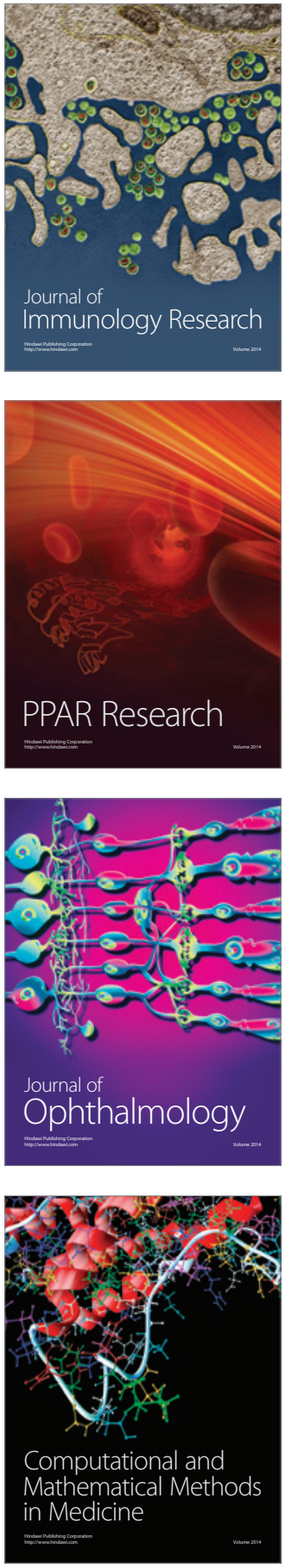

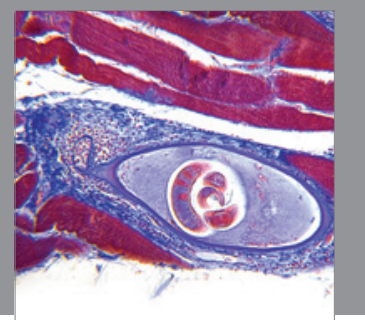

Gastroenterology

Research and Practice
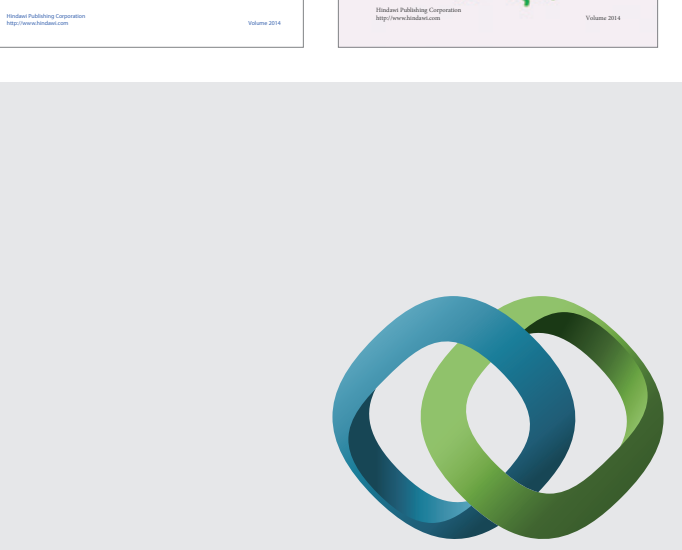

\section{Hindawi}

Submit your manuscripts at

http://www.hindawi.com
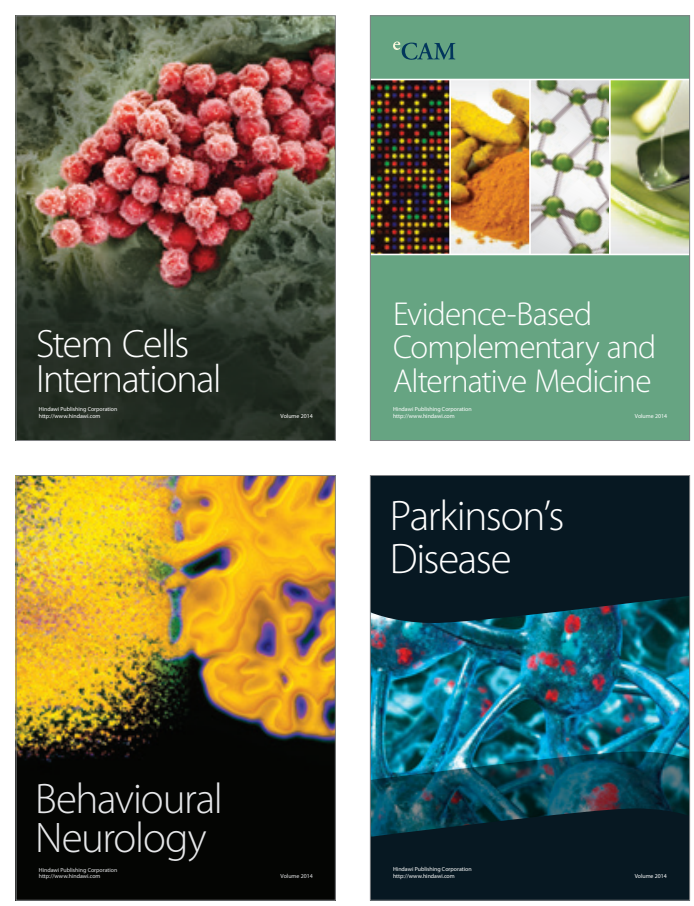

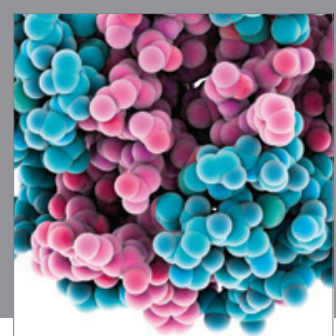

Journal of
Diabetes Research

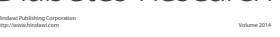

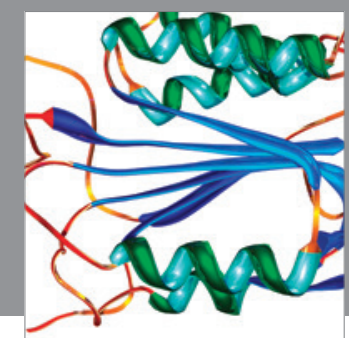

Disease Markers
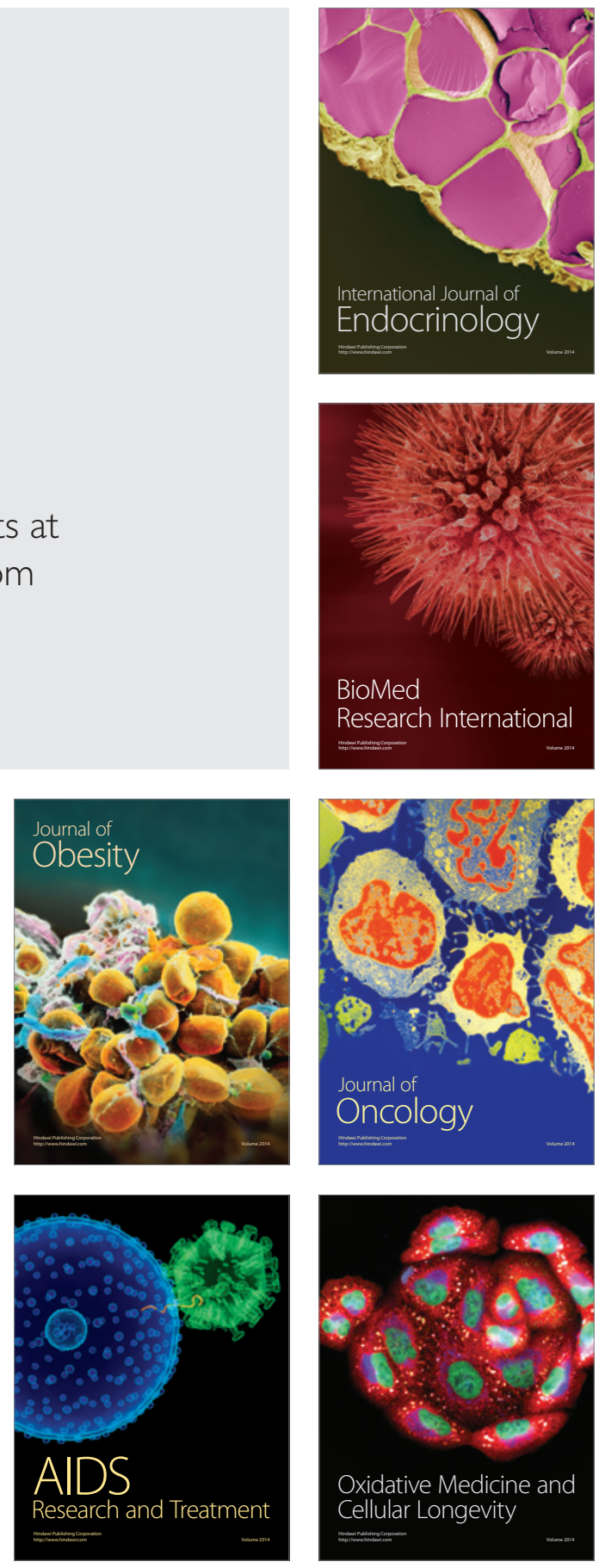